\title{
SOSIALISASI TENTANG BIDANG-BIDANG AKUNTANSI DAN PROFESI AKUNTAN PADA SISWA-SISWI JURUSAN AKUNTANSI DI SMKN 1 SUBANG
}

\author{
SOCIALIZATION ABOUT ACCOUNTING FIELDS AND THE \\ ACCOUNTANT TO ACCOUNTING DEPARTMENT STUDENTS \\ AT SMKN 1 SUBANG
}

\author{
Muhammad Rizal Satria ${ }^{1)}$, Ade Pipit Fatmawati ${ }^{2)}$, Marismiati ${ }^{3)}$, Indra Firmansyah ${ }^{4)}$ \\ ${ }^{1,2,3,4}$ Program Studi D4 Akuntansi Keuangan, Politeknik Pos Indonesia \\ ${ }^{1}$ Email: rizalstr@gmail.com
}

\begin{abstract}
Abstrak: Jurusan akuntansi di SMK merupakan salah satu jurusan yang memiliki respon positif dan banyak peminatnya, sehingga jumlah siswa jurusan akuntansi di SMK sangat signifikan. Namun, SMK sebagai penyumbang pengangguran tertinggi sehingga menimbulkan banyak pandangan negatif terhadap sistem pembelajaran di SMK, kemampuan lulusan SMK, pengelolaan SMK dan kebijakan pengembangan SMK. Menyadari hal tersebut, maka Kemendikbud dan SMK mensiasati dengan program BMW yaitu Bekerja, Melanjutkan dan Wirausaha. Namun Siswa-siswi SMK masih saja kebingungan ketika mulai mendekati masa kelulusan untuk menentukan masa depan mereka. Metode yang digunakan dalam melaksanakan kegiatan, yaitu: Memberikan Slide materi untuk bahan bacaan bagi para peserta berkaitan dengan topik sosialisasi; Melakukan sosialisasi/ceramah yang diberikan oleh narasumber-narasumber yang berkompeten dalam bidangnya; Kemudian dilakukan diskusi. Kegiatan ini dihadiri oleh 81 Siswa dan siswi jurusan akuntansi di SMKN 1 Subang dan dari hasil kuesioner menyatakan bahwa 58 siswa ingin Bekerja, 20 siswa ingin Melanjutkan kuliah dan 3 siswa ingin Wirausaha. Dari hasil kuesioner juga menyatakan bahwa pada dasarnya peserta memahami materi yang diberikan dan bermanfaat untuk menambah wawasan serta pengetahuan mereka di bidang akuntansi dan profesi akuntan.
\end{abstract}

Kata Kunci: Akuntansi, Akuntan, Profesi, SMK.

Abstract: The accounting department at SMK is one of the majors that has a positive response and has a lot of interest, so the number of students majoring in accounting at SMK is very significant. However, SMK as the highest contributor to unemployment has given rise to many negative views on the learning system in SMK, the ability of SMK graduates, SMK management and SMK development policies. Recognizing this, the Ministry of Education and Culture and Vocational High Schools anticipate the BMW program, namely Work, Continuing and Entrepreneurship. However, SMK students are still confused when they are approaching graduation to determine their future. The methods used in carrying out the activities, namely: Providing material slides for reading material for 
participants related to the topic of socialization; Conducting socialization/lectures given by competent resource persons in their field; Then a discussion was held. Community service was attended by 81 students and students majoring in accounting at SMKN 1 Subang and from the results of the questionnaire stated that 58 students wanted to work, 20 students wanted to continue their studies and 3 students wanted to be entrepreneurs. The results of the questionnaire also stated that basically the participants understood the material provided and it was useful to increase their insight and knowledge in the field of accounting and the accountant.

Keywords: Accounting, Accountant, Prefession, SMK.

\section{PENDAHULUAN}

Jurusan akuntansi di SMK merupakan salah satu jurusan yang memiliki respon positif dan banyak peminatnya, sehingga jumlah siswa jurusan akuntansi di SMK sangat signifikan. Ketertarikan siswa SMK sendiri tidak lepas dari gambaran masa depan lulusan setelah mengikuti proses Pendidikan di jurusan akuntansi (Agustina, Pertiwi, Ardiana, Ervina, \& Irwati, 2020). Pendidikan akuntansi di SMK dapat diartikan sebagai serangkaian proses belajar yang memiliki tujuan agar lulusan mampu menerapkan metode akuntansi sesuai dengan kaidah ilmu akuntansi yang dapat mendukung agar para lulusan siap menghadapi daya saing dalam bursa pasar tenaga kerja di industry 4.0.

Data BPS dalam beberapa tahun terakhir ini menyebut SMK sebagai penyumbang pengangguran tertinggi sehingga menimbulkan banyak pandangan negatif terhadap sistem pembelajaran di SMK, kemampuan lulusan SMK, pengelolaan SMK dan kebijakan pengembangan SMK. Kebijakan program revitalisasi SMK yang dimulai akhir tahun 2016 cukup memberi pengaruh positif dengan mulai menurunkan kontribusi pengangguran terbuka lulusan SMK di tahun 2017-2019 (Direktorat Sekolah Menengah Kejuruan, 2021). 


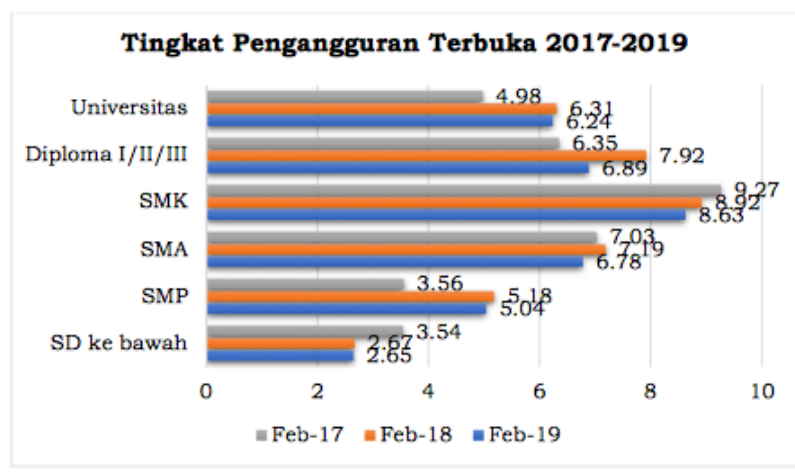

Gambar 1. Tingkat Pengangguran Terbuka SMK 2017-2019

Merujuk pada gambar diatas, menunjukkan bahwa tingkat angka pengangguran SMK masih tertinggi meskipun trennya menurun mengindikasikan bahwa daya saing dan posisi tawar lulusan SMK di pasar kerja belum menggembirakan. Dapat diasumsikan bahwa dunia usaha dan dunia industri masih memiliki alternatif lain sebagai pemasok tenaga kerja untuk level SMK dapat diperoleh dari jenjang lebih tinggi (PT) maupun jenjang yang setara (SMA/MA) ataupun jenjang di bawahnya (SD/SMP). Menyadari hal tersebut, maka Kemendikbud dan SMK mensiasati dengan program BMW yaitu Bekerja, Melanjutkan dan Wirausaha. Berikut adalah profil kompetensi bagi lulusan akuntansi dengan program BMW:

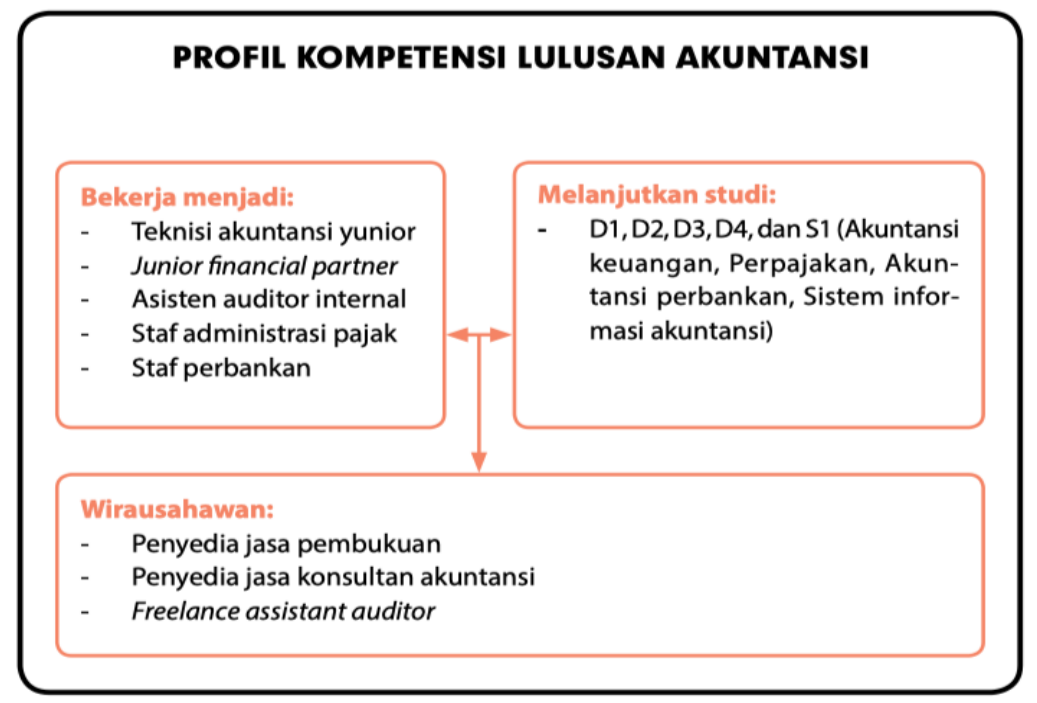

Gambar 2. Profil Kompetensi Lulusan Akuntansi 
Dengan adanya program BMW tersebut maka tuntutan dalam dunia usaha dan industri (DUDI) yang terus berkembang. Perkembangan dunia usaha dan industri diimbangi dengan perkembangan jenis-jenis bidang akuntansi, seperti akuntansi keuangan, akuntansi manejemen, akuntansi biaya, akuntansi sektor publik, akuntansi pajak, sistem akuntansi, teori akuntansi, serta khusus di Indonesia adanya konsep akuntansi Syariah (Nurhatyo \& Utami, 2015).

Bermacam-macamnya bidang akuntansi secara langsung membuat bertambahnya profesi akuntan khususnya di Indonesia. Pada umumnya terdapat empat jenis profesi akuntan yang ada di dunia usaha dan dunia Industri, yaitu akuntan pendidik, akuntan publik, akuntan manajemen dan akuntan pemerintah (Satria, 2019).

Keberagaman profesi akuntan dalam dunia usaha dan dunia industri memberikan pilihan bagi setiap siswa SMK untuk memilih terjun langsung ke dunia kerja yang diminatinya. Setelah lulus dari SMK, siswa-siswi yang mengambil jurusan akuntansi seharusnya sudah dapat menentukan pilihan karir yang bisa dijadikan langkah awal untuk menentukan karir yang dipilihnya.

Sesuai dengan program BMW yang dikembangkan oleh kemendikbud, maka terdapat tiga opsi yang dapat dipilih oleh lulusan SMK. Pertama yang bisa dijadikan pilihan adalah bekerja, yaitu langsung terjun ke dunia usaha dan industri dengan menjadi teknisi akuntansi yunior, junior financial partner, asisten auditor internal, staf administrasi pajak dan staf perbankan (Direktorat Sekolah Menengah Kejuruan, 2021).

Pilihan kedua adalah melanjutkan studi ke pendidikan yang lebih tinggi seperti D4/S1 yang linier dengan bidang akuntansi seperti Akuntansi keuangan, Perpajakan, Akuntansi Perbankan, Sistem Informasi Akuntansi. Ketika lulus dari jenjang sarjana, maka lulusan akan mulai berkarir menjadi supervisor akuntansi, akuntan senior dan supervisor auditor.

Pilihan ketiga yang dapat diambil oleh lulusan SMK adalah Wirausaha dengan menyediakan jasa pembukuan, menyediakan jasa konsultan akuntansi, dan freelance assistant auditor, namun dibutuhkan jam terbang yang tidak sebentar 
INTEGRITAS : Jurnal Pengabdian

Vol 5 No 2 Desember 2021

ISSN 2580 - 7978 (cetak) ISSN 2615 - 0794 (online)

serta pembekalan yang cukup dengan mengikuti pelatihan-pelatihan dari lembaga profesional.

Siswa-siswi SMK seringkali kebingungan ketika mulai mendekati masa kelulusan untuk menentukan masa depan mereka. Perlu keyakinan yang kuat dan kemantapan hati ketika memutuskan untuk mengambil langkah. Kegiatan Pengabidan Kepada Masyarakat (PKM) ini dilakukan untuk menggali sekaligus memberikan bekal pada siswa-siswi yang sedang menempuh Pendidikan di SMK jurusan Akuntansi tentang gambaran masa depan yang bisa mereka dapatkan dan tempuh kedepannya. Sehingga ketika sebelum mereka lulus sudah bisa menentukan akan kemana profesi dan karir yang mereka pilih.Kegiatan Pengabdian Kepada Masyarakat (PKM) ini dilakukan untuk menggali sekaligus memberikan bekal pada siswa-siswi yang jurusan Akuntansi di SMKN 1 Subang tentang gambaran masa depan yang bisa mereka dapatkan dan tempuh kedepannya. Sehingga sebelum mereka lulus sudah bisa menentukan profesi dan karir yang mereka pilih.

\section{METODE}

Berdasarkan permasalahan mitra diatas, maka tim PKM ingin membantu memberikan solusi akan permasalahan yang sedang dihadapi SMKN 1 Subang. Permasalahan yang dihadapi adalah siswa-siswi SMKN 1 Subang cenderung masih bingung setelah lulus sekolah nanti, mayoritas ingin bekerja namun saat pandemic seperti ini sulit mencari pekerjaan dan mereka tidak mau meninggalkan daerah Subang, sebagian lainnya ingin kuliah namun terhambat karena biaya, ada pula sebagian kecil memilih untuk berwirausaha namun belum memiliki modal.

Pelaksanaan kegiatan pengabdian kepada masyarakat ini dilaksanakan secara langsung di Aula SMKN 1 Subang pada hari Rabu, 2 Juni 2021 pada pukul 09.30 sampai dengan 12.00 WIB. Kegiatan ini dilaksanakan secara hybrid karena 2 pemateri hadir memberikan pemaparan secara online melalui Zoom sedangkan peserta sebanyak 81 Siswa dan siswi jurusan Akuntansi SMKN 1 Subang hadir secara offline. Kegiatan dilaksanakan dengan memenuhi dan mengedepankan protokol kesehatan. Berikut adalah undangan dari kegiatan PKM yang dilaksanakan: 


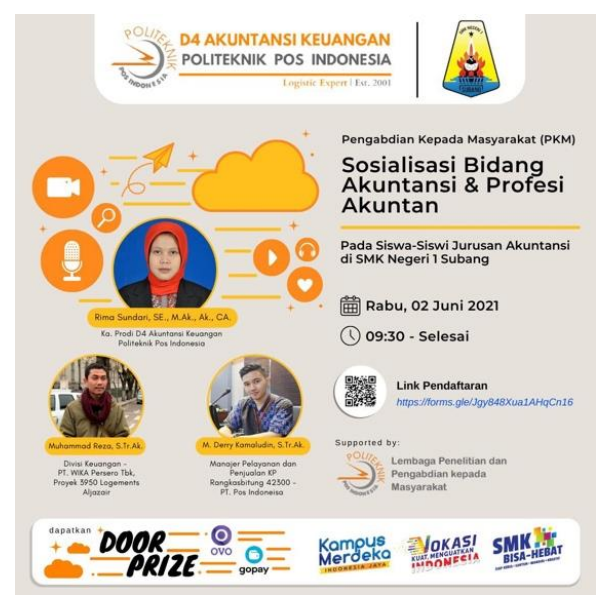

Gambar 3. Undangan Kegiatan PKM

Metode yang digunakan dalam melaksanakan kegiatan Pengabdian Kepada Masyarakat adalah melalui sosialisasi/ceramah. Langkah awal yang akan dilakukan adalah mengadakan penjajakan awal dan mohon izin kepada Kepala Sekolah SMKN 1 Subang bahwa akan melaksanakan kegaitan Sosialisasi Bidang Akuntansi dan Profesi Akuntan pada Siswa-siswi Jurusan Akuntansi. Kemudian mengirimkan undangan kepada para siswa siswi jurusan akuntansi di SMKN 1 Subang untuk mengikuti acara Sosialisasi. Setelah itu Tim PKM memberikan Slide materi untuk bahan bacaan bagi para peserta berkaitan dengan topik sosialisasi. Kemudian melaksanakan sosialisasi yang diberikan oleh narasumber yang kompeten di bidangnya. Kegaitan diakhiri dengan diskusi dan konsultasi.

\section{HASIL DAN PEMBAHASAN}

Kegiatan Pengabdian Kepada Masyarakat "Sosialisasi Bidang Akuntansi dan Profesi Akuntan" dilaksanakan pada hari Rabu, 2 Juni 2021 pukul 09.30 sampai dengan 12.00 WIB bertempat di Aula SMKN 1 Subang. Kegiatan ini dihadiri oleh 81 siswa-siswi jurusan Akuntansi kelas XII SMKN 1 Subang dengan didampingi oleh 4 wali kelasnya masing-masing. Serta dihadiri oleh Ibu Rika selaku Ketua Kompetensi Akuntansi dan Bapak Dedi Krisnandi selaku Wakil Kepala Sekolah bidang Kurikulum. Acara dibuka dengan sambutan dari Bapak Dedi Krisnandi selaku Wakil Kepala Sekolah bidang Kurikulum Berikut adalah tampilan kegiatan pembukaan acara Sosialisasi: 


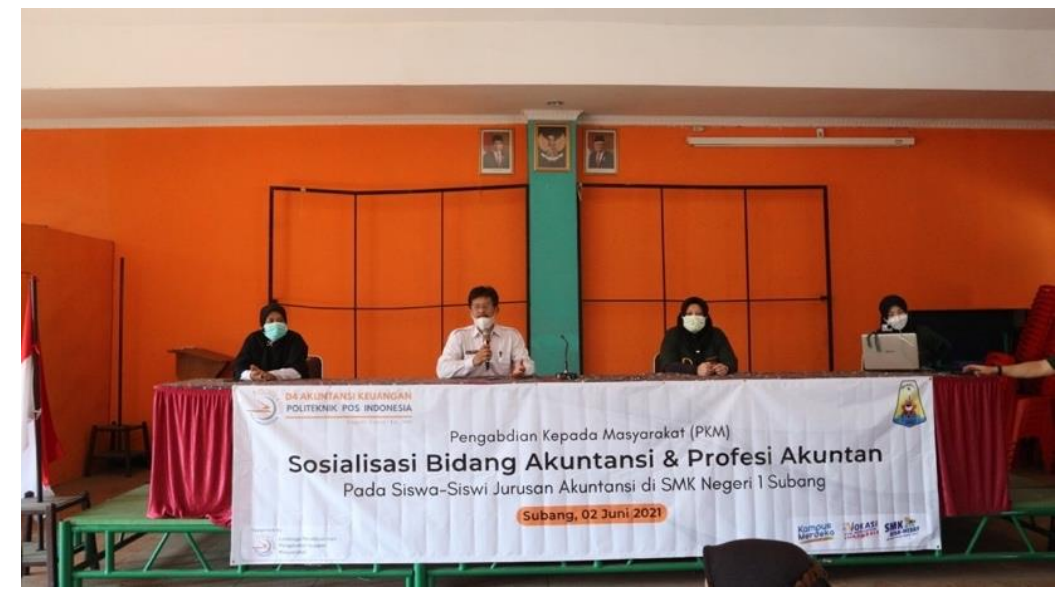

Gambar 4. Sambutan Wakasek Kurikulum SMKN 1 Subang

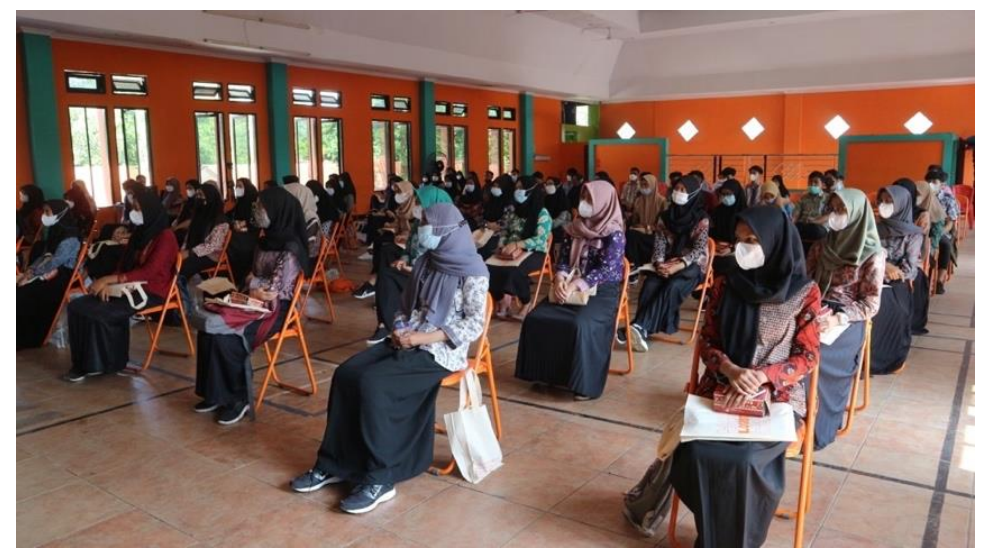

Gambar 5. Peserta Siswa Siswi Jurusan Akuntansi SMKN 1 Subang

Acara diikuti dengan tertib oleh para peserta, setelah sambutan dari Bapak Wakil Kepala Sekolah bidang Kurikulum, selanjutnya tim pengabdian sebagai panitia penyelenggara dan para narasumber yang kompeten dibidangnya mempresentasikan materi sosialisasi. Pemateri pertama adalah Ibu Rima Sundari, SE., M.Ak., Ak., CA. selaku Ketua Program Studi D4 Akuntansi Keuangan di Politeknik Pos Indonesia yang hadir secara langsung serta memberikan materi tentang bidang-bidang akuntansi serta gambaran dan prospek karir dari para lulusan D4 Akuntansi Keuangan.

Kemudian Sdr. M. Derry Kamaludin, S.Tr., Ak., selaku alumni dari D4 Akuntansi Keuangan Politeknik Pos Indonesia dan saat ini menjabat Manajer Pelayanan dan Penjualan Kantor Pos Rangkasbitung 42300 - PT. Pos Indonesia yang hadir secara online dan memberikan materi tentang pengalaman-pengalaman 
INTEGRITAS : Jurnal Pengabdian

Vol 5 No 2 Desember 2021

ISSN 2580 - 7978 (cetak) ISSN 2615 - 0794 (online)

kuliah Akuntansi dan memberikan gambaran tentang pekerjaan seorang Akuntan di dunia kerja industri.

Pemateri ketiga adalah Muhammad Reza, S.Tr., Ak. alumni dari D4 Akuntansi Keuangan Politeknik Pos Indonesia dan saat ini menjadi bagian dari Divisi Keuangan Proyek 3950 Logements Aljazair - PT. WIKA Persero Tbk yang hadir secara daring dan memberikan materi tentang pengalaman kuliah Akuntansi dan menceritakan pengalaman bagaimana sekarang bisa sampai di Aljazair, serta memberikan motivasi agar para siswa siswi dapat mencappai cita-cita yang tinggi.

Setelah pemaparan materi dari ketiga pemateri, dilakukan diskusi dan konsultasi yang dipimpin oleh tim pengabdian. Diskusi dan konsultasi ini terbuka untuk semua topik dibidang Akuntansi dan profesi Akuntan yang ingin diketahui oleh para peserta sosialisasi. Sesi diskusi dan konsultasi berjalan cukup aktif, pertanyaan yang diajukan cukup banyak dari para peserta. Rasa keingintahuan siswa cukup tinggi, hal tersebut tercermin dari banyaknya pertanyaan mengenai prosepek karir Akuntan. Materi tersebut di SMK memang belum menjadi materi utama, namun sudah dipelajari secara garis besar. Gambar kegiatan sosialisasi dapat dilihat pada gambar dibawah ini:
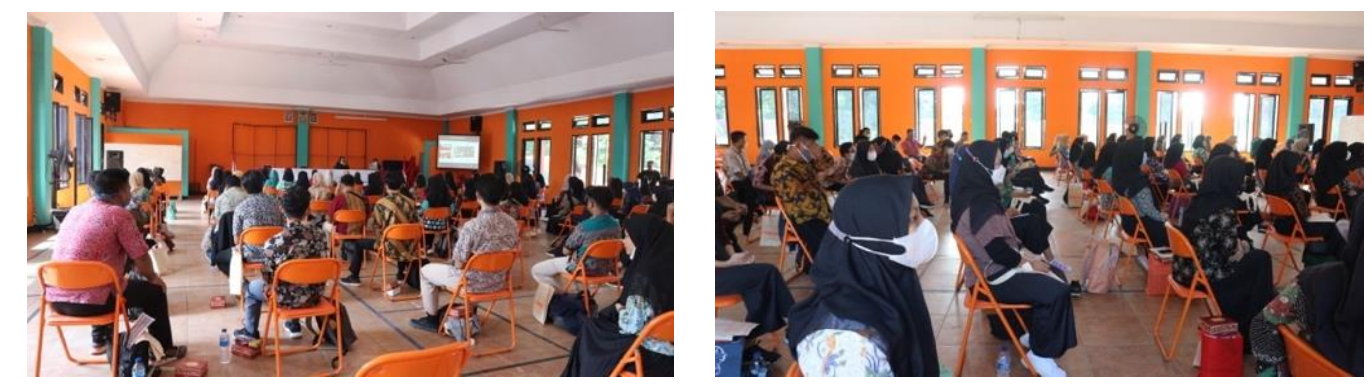

Gambar 6 \& 7. Peserta Sosialisasi mengikuti acara secara tertib

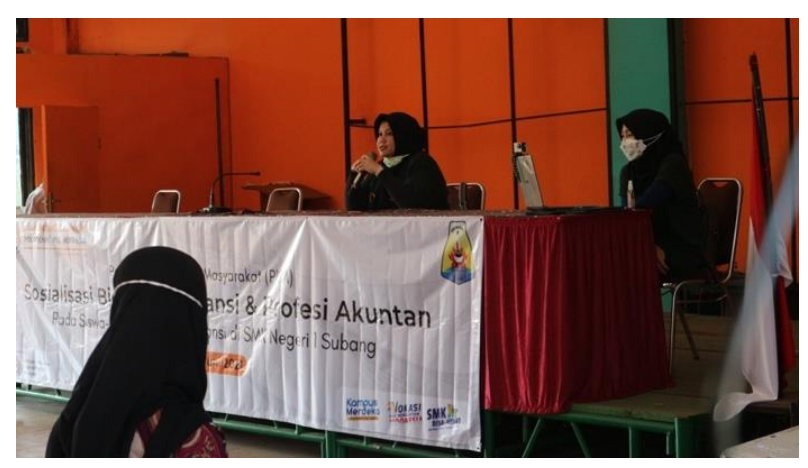

Gambar 8. Pemateri Mempresentasikan Materi Sosialisasi 

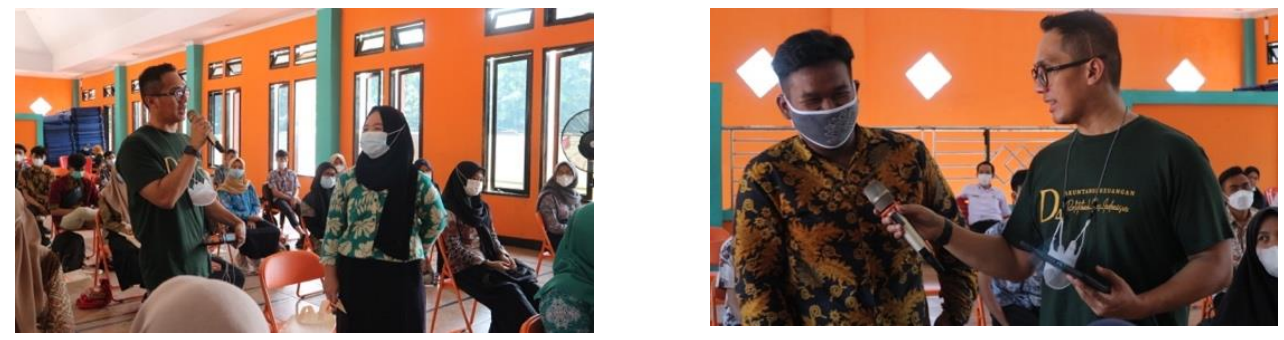

Gambar 9 \& 10. Peserta Aktif Mengikuti Diskusi dan Konsultasi
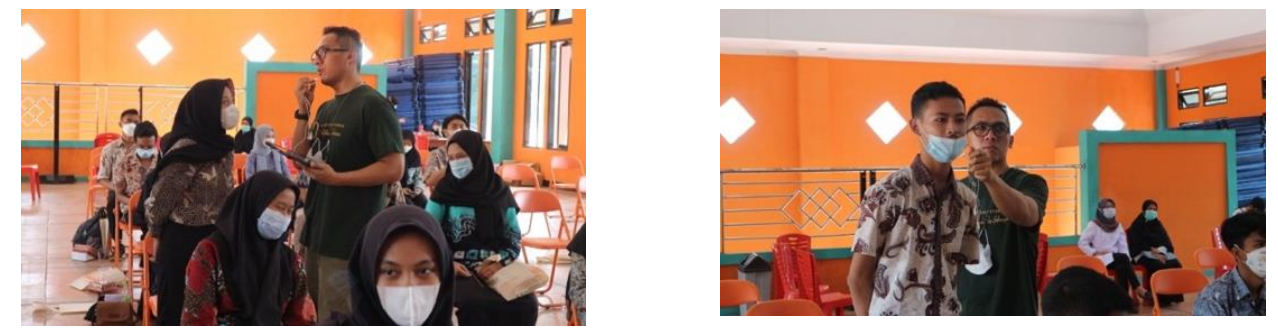

Gambar 11 \& 12. Peserta Aktif Mengikuti Diskusi dan Konsultasi

Setelah diskusi dan konsultasi, maka acara ditutup dengan foto Bersama antara panitia PKM, Pemateri, serta seluruh peserta sosialisasi. Kegiatan foto bersama tetap mengikuti protokol kesehatan dengan selalu menjaga jarak dan menggunakan masker. Gambar foto Bersama dapat dilhat dibawah ini:

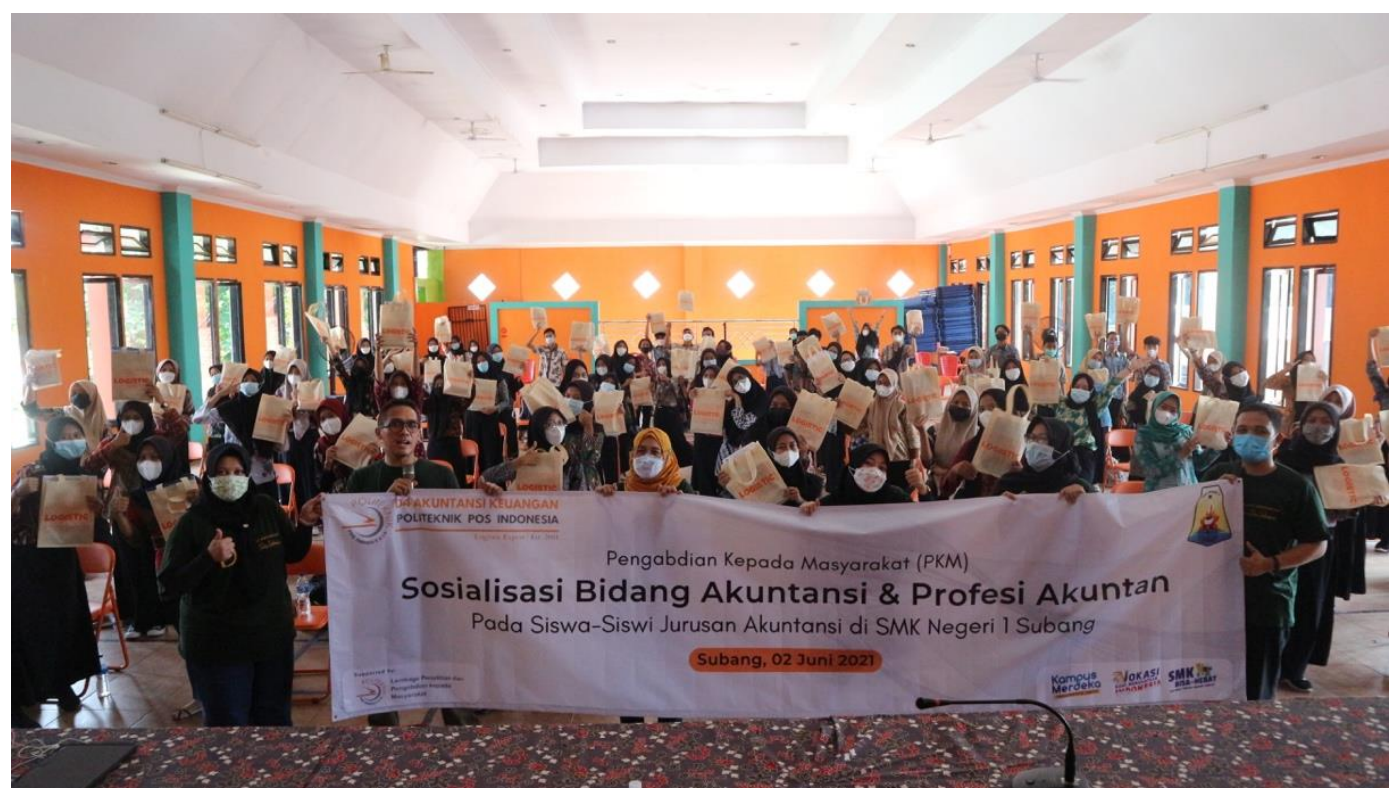

Gambar 13. Foto Bersama antara panitia PKM, Pemateri dan seluruh Peserta

Dari hasil kuesioner yang disebarkan pada peserta menyatakan bahwa pada dasarnya peserta memahami materi yang diberikan dan bermanfaat untuk menambah wawasan pengetahuan mereka di bidang akuntansi dan sudah tidak 
INTEGRITAS : Jurnal Pengabdian

Vol 5 No 2 Desember 2021

ISSN 2580 - 7978 (cetak) ISSN 2615 - 0794 (online)

bingung lagi dalam menentukan profesi yang akan mereka tempuh setelah lulus sekolah. Dari hasil kuesioner didapatkan juga bahwa 58 siswa ingin Bekerja, 20 siswa ingin Melanjutkan kuliah dan 3 siswa ingin Wirausaha. Para guru dan siswa juga mengharapkan kegiatan semacam ini dapat dilakukan di tahun yang akan datang.

\section{KESIMPULAN}

Kegiatan Pengabdian Kepada Masyarakat Sosialisasi Bidang Akuntansi dan Profesi Akuntan pada siswa-siswi jurusan Akuntansi SMKN 1 Subang berlangsung dengan lancar. kegiatan semacam ini sangat bermanfaat bagi siswa siswi SMKN 1 Subang. materi yang diberikan dapat menambah pemahaman dan wawasan mereka dibidang akuntansi dan profesi akuntan. banyak bidang akuntansi dan profesi akuntan yang sebenarnya belum mereka ketahui, materi yang diberikan dalam sosialisasi ini dapat menginspirasi dan menambah wawasan pengetahuan mereka. Mata pelajaran akuntansi di SMK hanya terfokus pada akuntansi keuangan yang terbatas penerapan akuntansi di perusahaan jasa dan dagang.

Guru-guru dan siswa siswi jurusan akuntansi di SMKN 1 Subang sangat mengharapkan sekali kegiatan sosialisasi dibidang akuntansi ini dapat dilaksanakan kembali di tahun yang akan datang. Kegiatan ini telah memberi peserta motivasi dan manfaat penting dari akuntansi sebagai dasar mereka menentukan prosepek karir yang akan mereka jalani. Dari hasil kuesioner menyatakan bahwa 58 siswa ingin Bekerja, 20 siswa ingin Melanjutkan kuliah dan 3 siswa ingin Wirausaha.

\section{UCAPAN TERIMA KASIH}

Kami ucapkan terimakasih sebesar-besarnya kepada SMKN 1 Subang, LPPM Politeknik Pos Indonesia, Program studi D4 Akuntansi Keuangan, dan seluruh Tim PKM yang telah banyak membantu hingga dapat terwujudnya acara PKM ini. 


\section{DAFTAR PUSTAKA}

Agustina, R., Pertiwi, D., Ardiana, M., Ervina, D., \& Irwati, W. (2020). Peningkatan Literasi Siswa SMK Pada Bidang-Bidang Akuntansi dan Jenis-Jenis Profesi Akuntansi. Abidumasy , 54-57.

Anna, Y. D., \& Rahayu, S. (2011). The Factors Affected Toward Profession Option as Accountant Public and Non Accountant Public Selected.

Arens, Alvin, Randal, E. J., Beasley, M. S., \& Wibowo, H. (2015). Auditing dan jasa assurance: pendekatan terintegrasi. Jakarta: Erlangga.

Direktorat Sekolah Menengah Kejuruan. (2021). Norma \& Standar Kompetensi Keahlian Akuntansi. Jakarta: Direktorat Jendral Pendidikan Vokasi Kementrian Pendidikan Dan Kebudayaan .

Farida, M. W. (2017). Memahami Kesadaran Peran Akuntan Pendidik Dalam Pembelajaran Akuntansi. Malang: Tesis Program Magister Sains Akuntansi Sekolah PAsca Sarjana Universitas Brawijaya.

Hansen, D. R. (2011). Akuntansi Manajerial. Jakarta: Salemba Empat.

Naukoko, A. P. (2017). Profesi Akuntan di Era Masyarakat Ekonomi ASEAN. Journal of ASEAN Studies on Maritime Issues, 3(4).

Nurhatyo, E., \& Utami, I. (2015). Riset Akuntansi Managemen; Telaah Tiga Perspektif. Jurnal Riset Manajemen, 2(1).

Satria, M. R. (2019). Pemilihan Jalur Karir bagi Mahasiswa Akuntansi di Politeknik Pos Indonesia. Ekono Insentif, 13(02), 125-133.

Yendrawati, R. (2017). Persepsi Mahasiswa dan Mahasiswa Akuntansi Mengenai Faktor-faktor yang Mempengaruhi Pemilihan Karir Sebagai Akuntan. Jurnal Ekonomi Universitas Islam Indonesia Yogyakarta, 5(2). 